\title{
Success coming - but only slowly
}

\section{Tsukuba}

A RUSH by private companies to build research institutes is finally bringing Tsukuba science city to life after nearly two decades when it seemed Tsukuba might never amount to anything more than handful of government research institutes spread out over a $20 \mathrm{~km}$ strip of paddy fields.

New statistics from a Tsukuba city office show that since 1985 the number of private research laboratories has more than tripled from fewer than 30 to more than 90 . Growth has been particularly dramatic in the past year: 18 new institutes opened in 1989, many more are under construction or planned and the number of company researchers and their support staff has risen dramatically to 5,000 - close to the number $(6,700)$ of government researchers.

The newcomers include giant pharmaceutical and chemical companies, such as Yamanouchi Pharmaceutical, Sankyo, Takeda Pharmaceutical, Kyowa Hakko, and Sumitomo Chemical, and electronic manufacturers such as NEC. Some of the biggest laboratories belong to foreign companies (see opposite). And although much of the research is product-orientated, there has also been a blossoming of company institutes devoted to much more basic research (see below). Around 50 small- to medium-sized factories producing high-technology products have also come in with the wave of private investment.

The surge of investment is good news for the government, which has spent more than a million million yen on a city in which until recently few people wanted to live. Plans to establish a science city in Tsukuba were hatched in the 1960 s when many government research institutes located in Tokyo were rundown and overcrowded and expansion was impossible because of skyrocketing land prices. Hence came the idea to make a mass move to a new site outside Tokyo. The student riots of the late 1960 s and early 1970 s also accelerated moves to establish a new university in Tsukuba.

By the early 1980s, 46 government research institutes and two universities had moved to the new site. But they were spread out over a vast area. The 'city' lacked a shopping centre and cultural facilities. The nearest railway station was a 20-minute bus or expensive taxi ride away. And the local country schools could not meet the exacting standards of academic parents. The result was that many

\section{Freeing the imagination}

NEC'S new laboratory in Tsukuba provides an insight into the fundamental changes that are going on in the research and development policies of major Japanese companies. The laboratory is vast by Japanese standards, providing an average of 100 square metres of space for each of the 160 staff plus all of the latest equipment. But more surprising is that much of the research going on there is not of immediate use to a major electronics and computer manufacturer.

Researcher Shigeru Tanaka, for example, is trying to understand how the brains of cats and monkeys process visual information using a mathematical model that describes the domain structure of magnetic thin films. (Tanaka sees striking similarities between the patterns of up-and-down magnetization in thin films and the stripes of occular dominance of the right and left eye in the visual cortex of the brain.) Toshikazu Takada spends his time simulating collisions between hydrogen molecules on a supercomputer. And another researcher plans to use pulsed lasers to investigate chemical reactions.

Such basic research is something completely new at a Japanese company laboratory. Hisatsune Watanabe, general manager of the laboratory, says that he sometimes has difficulty explaining to production managers the relevance of what is going on in Tsukuba. But the upper echelons of NEC are committed to backing basic research.

Until recently, NEC had only one research laboratory, in Kawasaki, not far from Tokyo. But now the company has five. A laboratory adjacent to a semiconductor plant in nearby Sagamihara acts as a 'liaison office' between the research and development sections of NEC and production. The new laboratory in Tsukuba and another in Princeton 'New Jersey' in the United States, on the other hand, are devoted to much more basic research. A fifth laboratory for computer technology, the NEC Kansai C\&C Research Laboratory, has just opened in Osaka.

Behind these moves to establish separate laboratories lies a deliberate strategy to create the freedom for more creative research by physically separating the people involved in production from those involved in basic research. Ironically, this is quite the opposite of what is going on in the United Kingdom and other Western countries, where government policy aims at bringing academics into closer contact with industry.

D.S.

researchers chose to spend four hours a day commuting from Tokyo rather than live in Tsukuba.

The situation is rapidly changing now. The influx of private researchers and their families helped to boost the population of Tsukuba city from 127,000 in 1985 to over 140,000 last year (the population is more than 174,000 if one includes outlying areas of the science city). New schools have been established to cater for the incomers. And although Tsukuba still has vast tracts of farm land, there is a shortage of land for housing - Japan's tax system encourages farmers to hold onto their farms.

Land prices have more than quadrupled in the past four years to over $¥ 1,000,000$ $(\$ 6,250)$ per tsubo (3.3 square metres) forcing some poorly paid researchers to set up house in country villages an hour's travel away. Many of the government researchers who previously scorned living

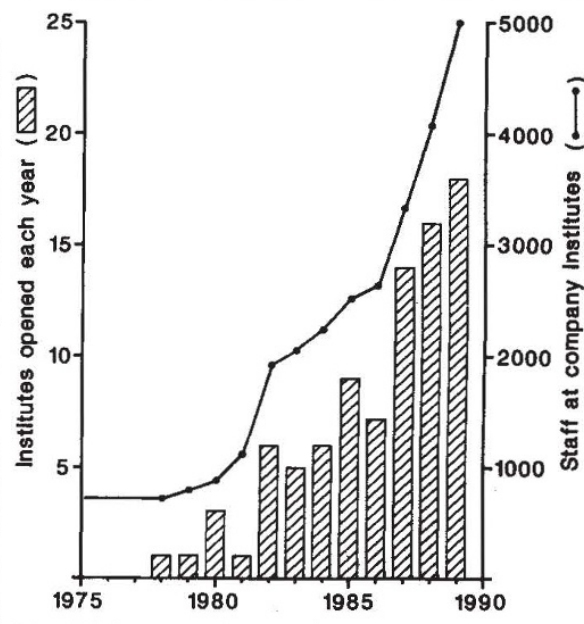

The histogram shows the number of private company research institutes opened each year in Tsukuba, and the graph shows the population of private company researchers and support staff in the city.

in Tsukuba are now looking for land and this has also helped drive up the prices.

So why the sudden rush to Tsukuba? The government-sponsored Tsukuba Science Expo (see Nature 314, 213-220; 1985 ) held in 1985 at a cost of $¥ 210,000$ million ( $\$ 1,300$ million at current exchange rate) acted as a great spur to private investment. Large department stores and hotels were built to cater for the 20 million visitors to EXPO, helping make Tsukuba a more liveable place. Also several of the companies have built their laboratories on the former EXPO site where cheap land was available.

Company officials cite two main reasons for their move to Tsukuba: availability of large tracts of cheap land not far from Tokyo, and access to facilities and information at government institutes. The synchrotron radiation source at the High Energy Physics Laboratory has many 